\title{
Положение ариан и донатистов в Африке после установления ромейского господства в регионе
}

\author{
Н.Е. Золотухина \\ Белгородский государственный национальный исследовательский университет, \\ Россия, 308015, г. Белгород, ул. Победы, 85 \\ E-mail: tretyakova_n_e@mail.ru
}

\begin{abstract}
Аннотация. Статья посвящена проблеме социального положения ариан и донатистов в условиях установления ромейской власти без углубления в догматические богословские вопросы. Основное внимание уделяется анализу цели военной кампании Велизария в Северной Африке и приводятся аргументы в защиту тезиса о том, что данная военная кампания не носила религиозного характера с целью подавления ариан. Анализируется количественный состав ариан среди солдат экспедиционного корпуса и их отношение к военной кампании. Акцентируется внимание на укрепление позиций донатистов в конце VI в. в византийской провинции Африка.
\end{abstract}

Ключевые слова: Северная Африка, Велизарий, ариане, донатисты.

Для цитирования: Золотухина Н.Е. 2020. Положение ариан и донатистов в Африке после установления ромейского господства в регионе. Via in tempore. История. Политология, 47 (4): 747-753. DOI: 10.18413/2687-0967-2020-47-4-747-753.

\section{The position of the Arians and Donatists in Africa after the establishment of Byzantine domination in the region}

\author{
Natalya E. Zolotukhina \\ Belgorod National Research University, \\ 85 Pobeda St., Belgorod, 308015, Russia \\ E-mail: tretyakova_n_e@mail.ru
}

\begin{abstract}
The article is devoted to the problem of the social position of the Arians and Donatists after the establishment of Byzantine domination without going into dogmatic questions. Attention is paid to the analysis of the purpose of Belisarius's military campaign in Africa and arguments are given in defense of the thesis that the military campaign was not religious in nature with the aim of suppressing the Arians. The quantitative composition of the Arians among the soldiers of the expeditionary corps and their attitude to the military campaign are analyzed. Attention is focused on strengthening the position of the Donatists at the end of the 6th century in the province of Africa. In the sources, the religious context of the conquest is poorly mentioned, as a rule, the goal of Belisarius's campaign is leveled by the theses that the vandals brought a lot of grievances to the romanized population without clarifying the confessional issue. North Africa is of particular interest for the study of late antique Christianity.
\end{abstract}

Keywords: North Africa, Belisarius, Arians, Donatists.

For citation: Zolotukhina N.E. 2020. The position of the Arians and Donatists in Africa after the establishment of Byzantine domination in the region. Via in tempore. History and political science, 47 (4): 747-753 (in Russian). DOI: 10.18413/2687-0967-2020-47-4-747-753.

Северная Африка представляет особый интерес для изучения позднеантичного христианства, специфика которого определяется наличием ряда факторов - раскол Карфагенской церкви и распространение донатизма, а также господство арианской церкви в пе- 
риод вандальского завоевания. Поскольку и ариане, и донатисты признавались еретиками, исследовательский интерес обусловлен вопросом их положения после установления ромейского господства в регионе.

Объектом настоящего исследования является проблема социального положения ариан и донатистов в условиях установления ромейской власти без углубления в догматические вопросы.

Церковный раскол в Карфагенской церкви произошел еще в начале IV в. Его главным действующим лицом на начальном этапе был епископ Нумидии Донат, от имени которого происходит название движения донатистов. Важное значение для донатистов имели их утверждения о том, что признаком истинной церкви является святость, проявляющаяся в личном совершенстве её служителей, и что действительны только те таинства, которые совершаются в церкви, а также что ранее совершенные таинства вне церкви недействительны [Дилигенский, 1961]. Спад движения донатистов приходится на период правления императора Гонория, когда они были лишены гражданских прав и права собираться для отправления своих богослужений. Взаимоотношения донатистов с вандалами остаются неясными. Вероятно, этот конфликт отошел на задний план, поскольку вандалы придерживались арианства.

По поводу происхождения арианства высказывались различные точки зрения. Например, В.В. Болотов отмечал связь арианства с оригенизмом [Болотов, 1910]. А.М. Иванцов-Платонов придерживался точки зрения о том, что арианство стало результатом борьбы различных течений александрийской школы [Иванцов-Платонов, 1881]. В 381 г. при императоре Феодосии Великом арианство было окончательно осуждено. Тем не менее, к тому времени идеи Ария получили широкое распространение среди федератов - готов и вандалов, а в Северной Африке с установлением вандальского господства лишь упрочились [Лебедев, 1916].

Имеющиеся источники V-VI вв. указывают на то, что на протяжении многих лет вандалы преследовали местное христианское население, а император Юстиниан, будучи праведным христианином и набожным человеком, активно боролся с ересью и считал унижения, которым подверглось христианское население Африки, невыносимыми [Кулаковский, 2003]. Возмущенный тем, что вандалы насильно крестили ортодоксальных христиан в арианство, пытали верующих, оскверняли храмы, он поставил своей целью освободить африканское население от ариан ${ }^{38}$. Таким образом, можно предположить, что одним из мотивов для завоевания императором Юстинианом Африки был религиозный: стремление освободить африканское романизированное христианское большинство от арианства. Также важно отметить стремление Юстиниана восстановить прежние границы Римской империи, что, вероятно, может быть более веской причиной для вандальской войны.

В историографии относительно основных причин вторжения Юстиниана в Северную Африку часто отмечается, в первую очередь, его религиозный характер. Например, Ш. Диль прямо считал эту военную кампанию крестовым походом [Diehl, 1896], a Вудворд - священной войной против ариан [Woodward, 1916].

Однако необходимо отметить, что в экспедиционных силах, находившихся под командованием Велизария, не менее 1000 солдат были приверженцами арианства (Procop., II. XIV, 12). Более того, несмотря на то, что Юстиниан являлся ревностным гонителем еретиков, в соответствии с эдиктом от 527 г. относительно готов-ариан, имеющих статус федератов, были применены снисхождения (Cod. Just. 1.5.12.17).

${ }^{38}$ Африканское духовенство стремилось предать гласности гонения со стороны вандалов, что можно наблюдать в труде Виктора Витенского «История гонений в африканской провинции» (Сorpus scriptorum ecclesiasticorum latinorum, vol. VII). 
Прокопий Кесарийский не дает нам упоминаний о том, что Велизарий в ходе кампании в Африке акцентировал какое-либо внимание на религиозной проблеме. При этом он отмечал, что христиане Африки перенесли много оскорблений со стороны вандалов (без упоминания их вероисповедания) ${ }^{39}$. По мнению Уолтера Кэги, Прокопий мог избегать указания на религиозную проблему по нескольким причинам: во-первых, потому, что не являлся приверженцем каких-либо конфессиональных споров; во-вторых, потому, что в этом отсутствовала необходимость, так как его интересовало изложение событий лишь с политической точки зрения; в-третьих - отношение Велизария и экспедиционного корпуса к арианам Африки не было принципиально негативным [Kaegi, 1965].

Несмотря на то, что солдаты-ариане представляли малую часть экспедиционного корпуса, на наш взгляд, они могли оказать определенное влияние на общую ситуацию, делая ее более мягкой и терпимой по отношению к местным арианам Африки (вандалам).

Стоит отметить, что в источниках также нет явного указания на то, что Велизарий угрожал или жестоко обращался с арианским духовенством в Африке. С приходом ромеев многие арианские священнослужители бежали из Карфагена. Прокопий Кесарийский повествует, что Велизарий вошел в Карфаген 15 сентября 533 г. Прежде чем разрешить своим солдатам войти в город, он напомнил, что африканцы прежде были римлянами, и что эти африканцы перенесли много оскорблений (он не был здесь конкретен) от рук вандалов, и именно по этой причине император вел войну с ними: «Ливийцы [романизированное африканское население] издревле являлись римлянами, оказались под властью вандалов не по собственной воле и испытали от этих варваров много беззаконий; именно поэтому василевс [Юстиниан] и начал войну с вандалами, и с их стороны [экспедиционного корпуса] было бы просто святотатством причинить зло людям, для освобождения которых (ибо такова причина войны) они двинулись против вандалов» (Procop., I. 20. 19-20). Когда новость о поражении Гелимера достигла Карфагена, арианские священники бежали (Procop., I. 21. 19-25).

Таким образом, мы видим, что у Прокопия отсутствуют упоминания о том, что арианские священники вынуждены были бежать из-за насильственных действий со стороны экспедиционного ромейского корпуса. Изложение Прокопия, вероятно, указывает на их естественный характер побега из Карфагена из-за страха. Последующие события (в 536 г.) показали, что влиятельное количество арианского духовенства осталось на свободе в Африке даже после установления ромейской власти. Также Велизарий предоставил бежавшим вандалам убежище в карфагенских храмах, что может являться важным доказательством политики умеренности и терпимости в отношении религиозных убеждений вандалов (Рrocop., I. 21.11).

Более того, анализ законодательных памятников Юстиниана показал, что Юстиниан разрешил арианскому духовенству сохранять свои церковные должности в течение определенного времени, в конце которого, в случае, если они будут перекрещены в ортодоксальное христианство, они не будут подвергаться смещению. Однако, в соответствии с письмом Папы Агапита I от 15 октября 535 г., сообщалось, что бывшие ариане и арианские священнослужители не могут быть приняты в христианское ортодоксальное духовенство, несмотря на желание императора.

Таким образом, данный тезис может указывать на стремление Юстиниана благоприятствовать переходу ариан в ортодоксальное христианство, так как он, вероятно, полагал, что таким образом арианская церковная собственность будет мирно передана в собственность официальной церкви, в чем прослеживается попытка следовать политике религиозной умеренности [Saumagne, 1892].

${ }^{39}$ При этом очевидно, что «христиане Африки» - это ортодоксы, а вандалы - ариане [Третьякова, 
Однако подобная умеренная политика не была поддержана североафриканскими священнослужителями, и реакцией на их позицию стало издание в 535 г. новеллы «Об африканской церкви» ${ }^{40}$, которая была направлена на имя префекта претория Африки Соломона [Иващенко, 1873]. Новелла касалась в первую очередь вопросов церковного имущества, а также социального положения донатистов и ариан - арианам, донатистам, иудеям, и другим лицам, не исповедующим православной веры, запрещалось совершать священнодействия, строить храмы, иметь епископов и клириков и проводить таинство Крещения, поскольку «эти секты осуждены не только нами [императором], но и прежними законами, и содержатся людьми нечестивыми и беззаконными» (Novellae, 37).

Также все еретики должны были быть отстранены от общественной деятельности и должностей. В отношении тех, кто являлся приверженцем никейского символа веры, но потом перешел в арианство или к донатистам, а после снова возвратился к ортодоксальной вере, запрещалось вступать на военную службу (Novellae, 37). Также донатистам и арианам не разрешалось иметь свои святилища и совершать обряды.

Новелла ознаменовала изменение в политике императора Юстиниана в отношении данного религиозного вопроса, поскольку, вероятно, император осознавал важность поддержки со стороны североафриканского духовенства. Следует отметить, что в это время была предпринята кампания против остготов в Италии и на Сицилии, в которой Африка играла важную роль тыла. Вероятно, в подобных условиях было важно обеспечить спокойствие в Африке. Тем не менее публикация новеллы имела свой результат. Солдатыариане экспедиционного корпуса, оставшиеся в Африке, были недовольны прекращением политики веротерпимости в отношении проведения религиозных обрядов.

Как мы отмечали ранее, важной причиной нестабильной ситуации внутри экспедиционного корпуса Велизария стало отсутствие выплаты жалований (Рrocop., II. 15. 55-56) и то, что многие солдаты женились на женщинах-вандалках, которые претендовали на земли, которыми ранее владели. Уолтер Кэги полагает, что доктринальные различия арианства и ортодоксального христианства не были достаточно сильной проблемой, чтобы спровоцировать мятеж среди ариан-солдат, причины крылись именно в социальноэкономической ситуации [Kaegi, 1965].

В 536 г. произошло восстание под предводительством Стотцы [Жюльен, 1950]. Ариане, начавшие мятеж, составляли лишь небольшую часть от общего числа войск, которые участвовали в нем. Их число было около 1000 чел. В дополнение к этому выступили 1000 вандалов (дезертиры из воинских частей вандалов, которые Юстиниан организовал для борьбы на Востоке), которые также предположительно были арианами (Procop., II. 14. 12). Таким образом, число ариан среди солдат составляло около 2000 чел. Всего количество экспедиционного корпуса солдат (исключая многочисленных местных рабов неопределенной религиозной веры, присоединившихся к мятежникам) в восстании составило 9000 чел. (Procop., II. 15. 4). Следовательно, ариане составляли менее четверти от числа мятежников. Упоминания ариан в источниках исчезают с подавлением восстания Стотцы.

Таким образом, едва ли предположения о том, что арианство укрепилось в Африке с установлением ромейского господства, могут быть основательны, равно как и те, что многие маврусии являлись арианами ${ }^{41}$.

В соответствии с законодательством Юстиниана донатистам также запрещалось иметь свои храмы, священнослужителей, а также проводить обряды. Однако сведения о донатистах активно начинают встречаться в источниках в период правления императора Маврикия. Для лучшего понимания этой ситуации отметим, что период правления этого императора характеризовался нестабильной внутренней и внешней ситуаций, в условиях

40 Публикация перевода Новеллы 37 Юстиниана I «Об Африканской церкви» с комментариями и историографическим обзором была подготовлена В.В. Серовым и Ю.А. Крейдуном [Серов, Крейдун, 2017].

${ }^{41}$ О предмете данных рассуждений подробнее см.: [Speel, 1960]. 
чего, вероятно, сам он видел необходимость поддержания внутреннего мира и порядка. Им были смягчены законы, принятые Юстинианом в отношении ереси и инакомыслящих, - к примеру, евреям разрешалось спокойно строить синагоги.

Из писем Папы Григория Великого мы узнаем, что в это время свои позиции усилило движение донатистов. С 591 по 596 гг. непрерывно в переписке Григория Великого обсуждалось усиление позиций донатистов. В соответствии с постановлением императора Маврикия, донатистам разрешалось иметь свои церкви и епископов (Greg., 1, 75), но при условии, что они [донатисты] не могли занимать посты религиозного руководства в провинции и должны были быть благосклонны к императорской администрации. Вся эта ситуация обернулась тем, что донатисты начали насильственно изгонять ортодоксальных священнослужителей.

Более того, данная ересь получила настолько широкое распространение, что многие давали согласие на крещение по донатистскому обряду. «Высшие ранги общества, которые были заражены этой инфекцией (имеется в виду донатизм), а также крупные землевладельцы использовали свое влияние, чтобы «посадить за руль» после них людей, зависящих от их полномочий» (Greg., 4, 41; 6, 34). В это время Папа Римский усилил влияние на Карфагенскую церковь. Когда он узнал (в 597 г.), что префект Нумидии Панталеон слишком ослабил меры против донатистов, и что их влияние возросло до такой степени, что православные священники изгоняются и крещенные ими перекрещиваются, то письменно поручил созвать местный собор. Проходил ли этот собор, и какие решения на нем были приняты - неизвестно. Также, в конце 594 или в 595 г., в Карфагене был проведен общий собор под председательством Карфагенского епископа Доминика в отношении вопроса о донатистах [Markus, 1991]. После этого упоминаний о донатистах в Африке в источниках не встречаются.

Таким образом, мы рассмотрели положение ариан и донатистов после установления ромейской власти в регионе. Вероятно, ошибочно полагать, что арианство укрепилось после прихода ромеев, как и то, что император Юстиниан и Велизарий с экспедиционным корпусом вели захватническую политику в отношении ариан. Подобные действия не являлись рациональными, поскольку в составе экспедиционного корпуса Велизария было около 1000 солдат-ариан.

В источниках слабо упоминается религиозный контекст завоевания; как правило, цель кампании Велизария нивелируется тезисами о том, что вандалы доставили много обид романизированному населению без уточнения конфессионального вопроса.

Говоря о восстании солдат, среди которых были ариане, представляется маловероятным искать в нем религиозную причину, так как наибольшее значение в ходе мятежа имел земельный вопрос, а также вопрос жалования.

Донатисты, как и все ереси, в соответствии с законодательством Юстиниана не имели права иметь церкви, священнослужителей, совершать обряды, однако с ослаблением политики императора Маврикия в отношении еретиков движение донатистов в некоторой мере укрепило позиции в конце VI в.

Все ереси в византийской Африке исчезли лишь вместе с христианством и имперской властью в целом в ходе арабского завоевания конца VII в.

\section{Список литературы}

1. Болотов В.В. 1910. Лекции по истории Древней Церкви. В 4-х томах. Том 3. СПб., 474.

2. Виктор Витенский. 2007. История гонений в африканской провинции. Москва. Электронная книга. URL: http://yakov.works/acts/05/marsel/istoriki_11.htm (дата обращения: 24 мая 2020).

3. Дилигенский Г.Г. 1961. Северная Африка в IV-V вв. Москва, Политиздат, 304.

4. Диль Ш. 1906. Юстиниан и византийская цивилизация в VI в. СПб., 188 с.

5. Жюльен Ш.-А. 1950. История Северной Африки. В 2-х томах. Том 1. Москва, Наука, 422. 
6. Иванцов-Платонов А.M. 1881. Религиозные движения на христианском Востоке в IV и V веках. Москва, 239.

7. Иващенко А.И. 1873. История Северо-африканской Церкви с 534 года до конца ее существования. Христианское чтение, 11: 461-531.

8. Кулаковский Ю.А. 2003. История Византии. В 3-х томах. Том 2. СПб., Алетейя, 402.

9. Лебедев Д.А. 1916. Вопрос о происхождении арианства. Богословский вестник, 5: 133-162.

10.Мягков Ю.Г. 1995. Юстиниан и «Ренессанс» Римской империи в VI в. Античный вестник, 3: 12-22.

11. Серов В.В. 2017. Новелла 37 Юстиниана I «Об африканской церкви». Христианство на Ближнем Востоке, 2: 37-50.

12. Третьякова Н.Е. 2016. К вопросу об установлении византийской власти в Северной Африке и проводимой политике Юстиниана Великого в регионе. Науковий вісник Дипломатичної академії України: 120-125.

13. Diehl Ch. 1896. L'Afrique byzantine. Histoire de la domination byzantine en Afrique (533-709). Paris, Ernest Leroux, 644.

14. Kaegi W.E. 1965. Arianism and the Byzantine Army in Africa 533-546. Tradatio, 21: 23-53.

15. Markus R.A. 1966. Reflections on Religious Dissent in North Africa in the Byzantine Period. Studies in Church History, 3: 140-149. 1: $159-166$.

16. Markus R.A. 1991 The Problem of «Donatism» in the VI C. Gregorio Magno e il suo tempo,

17. Merrills A.H. 2004. Vandals, Romans and Berbers: New Perspective on Late Antique North Africa. Ashgate, 316.

18. Saumagne Ch. 1892. Étude sur la propriété ecclésiastique à Carthage d'apres les novelles 36 et 37 de Justinien. Byzantinische Zeitschrift, 22: 77-87.

19. Speel C.J. 1960. The Disappearance of Christianity from North Africa in the Wake of the Rise of Islam. Church History, 29: 379-397.

20. Woodward E.L. 1916. Christianity and nationalism in the later Roman Empire. London, 106.

\section{References}

1. Bolotov V.V. 1910. Lekcii po istorii Drevnej Cerkvi [Lectures on the history of the Ancient Church]. V 4-h tomah. Tom 3. SPb, 474 (in Russian).

2. Viktor Vitenskij 2007. Istorija gonenij $\mathrm{v}$ afrikanskoj provincii [History of persecution in the African province]. Moskva. Jelektronnaja kniga. URL: http://yakov.works/acts/05/marsel/istoriki_11.htm (data obrashhenija: 24 maja 2020) (in Russian).

3. Diligenskij G.G. 1961. Severnaja Afrika v IV-V vv. [North Africa in the IV-V centuries]. Moskva, Politizdat, 304 (in Russian).

4. Dil' Sh. 1906. Justinian i vizantijskaja civilizacija v VI v. [Justinian and Byzantine civilization in the 6th century]. SPb., 188 (in Russian).

5. Zhjul'en Sh.-A. 1950. Istorija Severnoj Afriki [History of North Africa]. V 2-h tomah. Tom 1. Moskva, Nauka, 422 (in Russian).

6. Ivancov-Platonov A.M. 1881. Religioznye dvizhenija na hristianskom Vostoke v IV i V vekah [Religious movements in the Christian East in the 4th and 5th centuries]. Moskva, 239 (in Russian).

7. Ivashhenko A.I. 1873. Istorija Severo-afrikanskoj Cerkvi s 534 goda do konca ee sushhestvovanija [History of the North African Church from 534 to the end of its existence]. Hristianskoe chtenie [Christian reading], 11: 461-531 (in Russian).

8. Kulakovskij Ju.A. 2003. Istorija Vizantii [History of Byzantium]. V 3-h tomah. Tom 2. SPb., Aletejja, 402 (in Russian).

9. Lebedev D.A. 1916. Vopros o proishozhdenii arianstva [The question of the origin of Arianism]. Bogoslovskij vestnik [Theological Herald], 5: 133-162 (in Russian).

10. Mjagkov Ju.G. 1995. Justinian i «Renessans» Rimskoj imperii v VI v. [Justinian and the «Renaissance» of the Roman Empire in the 6th century]. Antichnyj vestnik [Antique Herald], 3: 12-22 (in Russian).

11. Serov V.V. 2017. Novella 37 Justiniana I «Ob afrikanskoj cerkvi» [Novella 37 Justinian I «On the African Church»]. Hristianstvo na Blizhnem Vostoke [Christianity in the Near East], 2: 37-50 (in Russian). 
12. Tret'jakova N.E. 2016. K voprosu ob ustanovlenii vizantijskoj vlasti v Severnoj Afrike i provodimoj politike Justiniana Velikogo $\mathrm{v}$ regione [On the question of the establishment of Byzantine power in North Africa and the policy pursued by Justinian the Great in the region]. Naukovij visnik Diplomatichnoï akademiï Ukraïni [Scientific Bulletin of the Diplomatic Academy of Ukraine]: 120-125 (in Russian).

13. Diehl Ch. 1896. L'Afrique byzantine. Histoire de la domination byzantine en Afrique (533-709). Paris, Ernest Leroux, 644.

14. Kaegi W.E. 1965. Arianism and the Byzantine Army in Africa 533-546. Tradatio, 21: 23-53.

15. Markus R.A. 1966. Reflections on Religious Dissent in North Africa in the Byzantine Period. Studies in Church History, 3: 140-149.

16. Markus R.A. 1991 The Problem of «Donatism» in the VI C. Gregorio Magno e il suo tempo, 1: $159-166$.

17. Merrills A.H. 2004. Vandals, Romans and Berbers: New Perspective on Late Antique North Africa. Ashgate, 316.

18. Saumagne Ch. 1892. Étude sur la propriété ecclésiastique à Carthage d'apres les novelles 36 et 37 de Justinien. Byzantinische Zeitschrift, 22: 77-87.

19. Speel C.J. 1960. The Disappearance of Christianity from North Africa in the Wake of the Rise of Islam. Church History, 29: 379-397.

20. Woodward E.L. 1916. Christianity and nationalism in the later Roman Empire. London, 106.

\section{ИНФОРМАЦИЯ ОБ АВТОРЕ}

Золотухина Наталья Евгеньевна, аспирант кафедры всеобщей истории Белгородского государственного национального исследовательского университета, г. Белгород, Россия

\section{INFORMATION ABOUT THE AUTHOR}

Natalia E. Zolotukhina, Postgraduate Student, Department of General History, Belgorod National Research University, Belgorod, Russia 